\title{
Three-component Particle Image Velocimetry in a Generic Can-type Gas Turbine Combustor
}

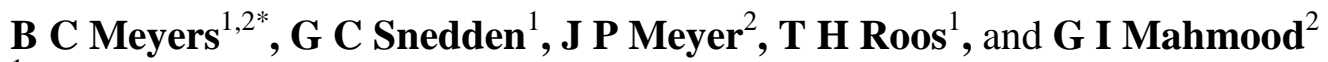 \\ ${ }^{1}$ Aeronautics Competency, Defence, Peace, Safety and Security, Council for Scientific and \\ Industrial Research, Pretoria, South Africa \\ ${ }^{2}$ Department of Mechanical and Aeronautical Engineering, University of Pretoria, Pretoria \\ South Africa
}

\begin{abstract}
A stereoscopic particle image velocimetry (PIV) system was used to obtain the velocity field of a can-type combustor in the non-reacting condition. In order for these measurements to be taken, an optically accessible can-type forward flow combustor was manufactured. The combustor has a 10 -vane swirler in the dome as well as a primary zone with six $9.5 \mathrm{~mm}$ holes, a secondary zone with eight $5 \mathrm{~mm}$ holes and a dilution zone with ten $11.8 \mathrm{~mm}$ holes. The two cooling rings have 30 and $50 \times 1.2 \mathrm{~mm}$ holes and are placed between the three zones. The main flow features were captured such as the recirculation zones and jets. The more subtle features such as flow entering the swirler, entering the dilution holes from

* Corresponding author: Aeronautics Competency, Defence, Peace, Safety and Security, Council for Scientific and Industrial Research, PO Box 395, Pretoria,0001, South Africa email: bmeyers@csir.co.za
\end{abstract}




\section{B C Meyers, G C Snedden, J P Meyer, T H Roos, and G I Mahmood}

the annulus, and converging into smaller annuli around the secondary and dilution zones were also evident in some sections of the data. An unexpected flow recirculation was observed in the dilution zone. The departure of the flow from the recirculation regions to join the bulk flow in the dilution zone was also shown.

Keywords: Particle Image Velocimetry, Combustor, Velocity, Streamlines

\section{INTRODUCTION}

A number of different experiments have been performed using the experimental can-type combustor test rig [1-3] previously. Problems became evident when comparing computational fluid dynamics (CFD) simulations with the actual experimental results obtained. Specific inconsistencies observed were the incorrect prediction of the temperatures and pattern factors and, after the PIV data was collected, the failure to predict some flow phenomena such as the recirculation zone that is present in the dilution zone of this combustor. It is a general problem that there are inconsistencies between experimental work and CFD solutions [4], and even some empirical predictions [5] of gas turbine combustors. Vakil and Thole [4] experienced an underprediction of turbulence levels while Archer and Gupta [5] encountered a significant difference between the calculated swirl numbers using the velocities and those predicted from 


\section{Three-component Particle Image Velocimetry in a Generic Can-type Gas Turbine} Combustor

the geometrical relationship derived from the swirler vane angle alone.

In most CFD cases, a non-reacting run is done first in order to ensure that the turbulence model is predicting the flowfield and the position of the important flow phenomena correctly $[4,6]$. This step is important because the combustion characteristics and the correctness of the reacting flow results are dependent on the flow characteristics $[5,7]$. Combustion CFD solutions often compare poorly with experimental values owing to inaccuracies in both flow modeling as well as in combustion modeling. This makes CFD a less reliable tool for combustor design than it is for other components.

Due to the CFD shortfalls, reliable experimental data on combustors is required for at least three reasons $[4-6,8,9]$ : Firstly, to obtain insight into the mechanisms of the flow in order to choose more appropriate models before performing numerical runs; secondly, to compare results in order to test and validate current, new and modified models, which are introduced

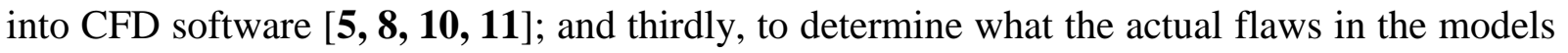
are and to determine which features are over- or underpredicted or not predicted at all.

In the past, other data sets $[\mathbf{4 , 6 , 8 - 1 2}]$ have been collected for the purpose of CFD validation and improvement.

Various combustor configurations as well as a variety of conditions have been used to create experimental data sets. The data sets have been varied according to the air supply 


\section{B C Meyers, G C Snedden, J P Meyer, T H Roos, and G I Mahmood}

characteristics, the presence of a combustion reaction (reacting flow) or not (non-reacting or isothermal flow), the fuel type and delivery in the reaction, the outlet configuration as well as the physical geometry of the combustor. Various methods were also used to collect the data, which then also determined the type, quality and quantity of experimental results available.

Some flowfield data was collected in experiments with no reaction taking place. These experiments showed the effect of varying set-ups on the flow conditions $[4,13]$. For some experiments, flowfield data was collected in both the reacting and non-reacting set-ups $[5,7,8,10,12,14]$, while for others, the flowfield was only captured in the reacting set-up $[6,9,11]$.

Archer and Gupta [5] and Li and Gutmark [7] used a Three-component PIV system to plot the axial velocity field over an area in the recirculation zone and the axial and tangential velocities along various cross-sectional diameters. Full three-component velocity fields on a plane in the recirculation zone were measured and plotted by Li and Gutmark [13].

Of the combustor experiments that were meant to be used for can-type combustor comparison, some only included the swirler with no primary, secondary, dilution or cooling holes $[\mathbf{5}, \mathbf{7}, \mathbf{1 1 - 1 3}]$. Some of the experiments had a swirler and one set of holes $[\mathbf{6}, \mathbf{8}]$. There were experiments that had circular liner shapes $[\mathbf{6 , 8}, \mathbf{1 3}]$, but more of the liners seem to be approximations of a circular liner such as octagonal [7], rectangular or square $[\mathbf{5 , 1 1}]$ or 


\section{Three-component Particle Image Velocimetry in a Generic Can-type Gas Turbine} Combustor

circular with flat windows inserted $[\mathbf{1 2}, \mathbf{1 4}]$.

In this study, the flowfield in an atmospheric pressure gas turbine combustor was measured using a stereoscopic particle image velocimetry (PIV) system in order to validate non-reacting run in the modeling process. Similar to Carl et al. $[\mathbf{1 0}]$, this study attempted to ensure that as many of the factors that influence the combustor flow should be included in the tests. However, where Carl et al. [10] performed their experiments in an annular combustor segment, in this case, data from a full cylindrical can-type combustor including swirler, primary, secondary and dilution holes as well as the cooling holes were present in a Perspex flow visualization combustor.

Therefore, the purpose of this study was to collect velocity data on a non-reacting can-type combustor, which can be used to validate CFD results, and to validate the CFD design methodology for combustors, in order to ensure that CFD can be used as a reliable design tool for gas turbine combustors. Furthermore, the main flow features and more subtle features are identified, summarized and discussed.

A steady-state experimental test case was created for these purposes. The test case was created with the intention that, when used for CFD comparison, the CFD modeling would be of the whole combustor and casing with the inlet plane upstream of the combustor liner as a boundary condition. Thus removing the need for air flow splits (the division of the provided 
B C Meyers, G C Snedden, J P Meyer, T H Roos, and G I Mahmood

air between the various hole sets) as a boundary condition and allowing the CFD to calculate the air flow splits. Due to the constant improvement in computing capability, this is a solvable problem using the current technology and eliminates the influence of potentially erroneous air flow split boundary conditions on the results.

\section{EXPERIMENTAL SET-UP}

\section{$2.1 \quad$ Test rig}

The gas turbine combustor test rig consisted of a fan run by an $11 \mathrm{~kW}$ motor to supply the air for combustion. The fan was attached to a set of pipes, which housed an orifice plate for flow rate measurement and allowed the flow to develop, with the combustor liner placed at the end of the pipes at the outlet. The combustor then exhausted to atmosphere. Fig. 1 shows a schematic diagram of the test rig.

The combustor liner is a generic can-type combustor, which contains all of the components that are needed to influence the flow as required in a combustor. As described by Shakariyants et al. [15], and can be seen in Fig. 2 from Lefebvre and Ballal [16] and NREC [17], the key components of a generic combustor are: a diffuser, casing, liner, fuel-air preparation unit (such as a fuel injector and swirl generating device (swirler)) and cooling arrangements. A typical in service production can -type combustor is that of the Rolls Royce T56 engine. A photograph 


\section{Three-component Particle Image Velocimetry in a Generic Can-type Gas Turbine} Combustor

and schematic (Gouws [18]) of the T56 liner are shown in Fig. 3.

The combustor liner in this study has a single swirler in the upstream dome end. A metal combustor was used in the test rig for reacting tests. A transparent replica of the metal combustor was manufactured such that the combustor liner's inner diameters and holes were identical to the metal combustor. Due to the slightly thicker walls, the outer diameter was not the same as the metal liner thus the annulus hydraulic diameter was matched. The transparent sections were manufactured from Perspex and the other plastic parts were manufactured from Ertacetal C. Fig. 4 provides a detailed drawing of the Perspex combustor.

The primary, secondary and dilution zones had $6 \times \varnothing 9.5 \mathrm{~mm}, 8 \times \varnothing 5.0 \mathrm{~mm}$ and $10 \times \varnothing 11.8 \mathrm{~mm}$ holes respectively. Between the primary and secondary cylinders were $30 \times \emptyset 1.2 \mathrm{~mm}$ cooling holes and there were $50 \times \emptyset 1.2 \mathrm{~mm}$ cooling holes between the secondary and dilution cylinders. The swirler was a $7 \mathrm{~mm}$ deep annular swirler with 10 helical vanes with a pitch of $60 \mathrm{~mm}$ at the mean radius. A detailed drawing of the swirler is provided

in Fig. 5. The combustor liner fitted inside a cylindrical casing with an inner diameter of $121.2 \mathrm{~mm}$. The fuel injector is situated in the central hole of the swirler with a $16 \mathrm{~mm}$ diameter fuel pipe extending upstream. 


\section{B C Meyers, G C Snedden, J P Meyer, T H Roos, and G I Mahmood}

\subsection{Instruments}

A TSI stereoscopic PIV system was used for velocity field measurements. It had a dual laser head enabling a minimum of $1 \mu \mathrm{s}$ pulse separation time between laser flashes. The dual laser heads were Big Sky Laser CFR 200s (energy output of $190 \mathrm{~mJ}$ for about $6 \mathrm{~ns}$ ) attached to frequency doubling and alignment optics. These optics enable both laser heads to emit a beam through the same outlet and to convert the $1064 \mathrm{~nm}$ wavelength to a $532 \mathrm{~nm}$ wavelength. The laser beam was then passed into a laser arm, which placed the light in the required position. A $-25 \mathrm{~mm}$ focal point cylindrical lens turns the beam into a sheet and a $500 \mathrm{~mm}$ focal point spherical lens focused the sheet to give it a sheet thickness of approximately $1.5 \mathrm{~mm}$ in the test section.

The two cameras used were Powerview 4M Plus grayscale CCD cameras each with a 2048 x 2048 pixel array and 12 bit output. The cameras were fitted with Nikon AF Nikkor $28 \mathrm{~mm}$ f/2.8D lenses. These cameras were attached to a rail facing the test section with the Sheimflüg angle satisfied for PIV data collection. Both cameras were on the same side of the laser sheet with the top camera in back scatter and the bottom camera in forward scatter.

The TSI software Insight3G [19] was used to analyze the images captured and Tecplot [20] was used to average the data. 


\section{Three-component Particle Image Velocimetry in a Generic Can-type Gas Turbine} Combustor

\subsection{Experimental details}

In order to capture the flow field throughout the combustor length, six experiments were performed. Three experiments were performed in line with (axially through) the holes, one in each of the zones (labeled $\mathrm{A}$ to $\mathrm{C}$ in Fig. 6a), and another three in between the holes (azimuthally) of the three zones (labeled D to F in Fig. 6a). Due to the different number of holes in each of the liner zones, the planes in between the holes were at different angular displacements from the plane in line with the holes. In the Primary zone (experiment D) the measurement plane was at $30^{\circ}$ to the plane in line with the holes while the secondary (experiment E) and dilution zone (experiment F) planes were at 22.5 and $18^{\circ}$ respectively. An axial view of the experimental planes is given in Fig. 6b. The laser sheet was aligned with the axial flow direction of the combustor liner for each of the experiments performed (A to F). Planes A to $\mathrm{C}$ in Fig. 6a show the positions of the data shown in Fig. 10 while planes D to F show the positions of the data in Fig. 11.

The cameras were required to be approximately $200 \mathrm{~mm}$ away from the combustor. This distance was chosen firstly, to fill as much of the camera frame with the region of interest in the combustor as possible, and secondly, because the smoke particles did not reflect light with enough intensity to place the cameras further away. The f-number was set to 2.8 .

The flow was seeded using vapour ("smoke") produced from heating oil. The smoke 


\section{B C Meyers, G C Snedden, J P Meyer, T H Roos, and G I Mahmood}

particle size could not be measured, however, it has been indicated by Melling [21] that oil smoke particles are of the order of $1 \mu \mathrm{m}$ in diameter. TSI classes oil smoke in the 0.05 to $1 \mu \mathrm{m}$ diameter range.

During the experiments the mass flow rate was set at $0.056 \mathrm{~kg} / \mathrm{s}$ with an inlet $\mathrm{Re}$ of $3.17 \times 10^{4}$. All the experimental flow characteristics are given in Table 1. Although there is no diffuser as such, this combustor is most similar to a dump diffuser setup and thus Re values in the range of $9.2 \times 10^{4}$ to $1.6 \times 10^{5}$ are common at the inlet to the diffuser [16]. The Reynolds number and air mass flow rate in this combustor are lower than would be expected at the inlet of most combustors, however, this is not expected to affect the use of the data to evaluate the relevance of CFD turbulence models in the liner flows with swirling and jet flow interactions. As the Reynolds number is above the generally accepted transition value and the nature of the flows in the combustor are highly turbulent and attached, the low inlet Reynolds number should not affect the ability of the CFD to predict these flows. Note should be taken, however, as reported by Lefebvre and Ballal [16], that "care must be taken during component testing when air densities may be close to normal ambient and Reynolds numbers are much lower than on the engine. Measurements of performance carried out at such conditions could give pessimistic results". As for the air mass flow rate, the combustor liner was designed for low flow rates $(0.1 \mathrm{~kg} / \mathrm{s})$ according to Lefebvre and Ballal [16] and NREC [17] design methods. 


\section{Three-component Particle Image Velocimetry in a Generic Can-type Gas Turbine} Combustor

Furthermore, it was demonstrated in the TechClean project of JAXA (Japan Aerospace Exploration Agency), during the development of their RQL annular combustor, that the modifications inferred from the combustion tests with can type combustors and atmospheric test conditions successfully led to the improvement of the combustion performance under practical conditions [22].

The pressure loss factor given in Table 1 denotes the flow resistance introduced into the airstream between the compressor outlet and turbine inlet by the combustor liner. The Pressure loss factor is given by $\Delta P_{L} / q_{\text {ref }}$. Similarly, the Overall pressure loss is given by $\Delta P_{L} / P_{3}$ [16].

The PIV images were analyzed using a Recursive Nyquist grid engine where two passes were performed with $50 \%$ overlap. The first pass was done with $64 \times 64$ pixel interrogation windows while the second was done with $32 \times 32$ pixel interrogation windows. The FFT correlation was used to generate the vector field while the sub-pixel accuracy was obtained using a Gaussian peak fit. No vector validation or conditioning was applied to the data, however, the vectors above $80 \mathrm{~m} / \mathrm{s}$ were removed in post-processing due to their clear correlation with the positions of image blooming (the extension of the regions of overexposure of the CCD chip image into the surrounding pixels due to excessive light). The characteristics of the PIV setup are given in Table 2 .

For each experiment, 720 three-component vector fields were averaged to get a steady-state 


\section{B C Meyers, G C Snedden, J P Meyer, T H Roos, and G I Mahmood}

vector field that represented the velocities in each zone.

\subsection{Uncertainty analysis and verification}

Li and Gutmark [7] stated that the uncertainty of PIV is greater than that of laser doppler velocimetry (LDV), which is taken as $\pm 5 \%$ and thus was assumed to be of the order of \pm 5 $10 \%$.

In order to get an indication of the validity of the PIV data for this study, it was compared with a known technique of velocity measurement. A comparison of uniform flow exiting of the test rig without a liner was measured using a pitot tube and the PIV system. The velocity profile comparison is given in Fig. 7. The pitot tube velocity profile has error bands consisting of the instrument error of the pitot tube $( \pm 1.1 \%)$ and the uncertainty of the velocity due to the uncertainty involved with setting up a repeated air mass flow rate $( \pm 0.4 \%)$. The velocity profile at the same cross-section obtained from an average of 735 PIV points per cell is plotted on the same graph. The scatter bands on the PIV profile has a $95 \%$ confidence interval for the PIV sample at each cell.

At the core of the flow, the pitot tube and the PIV profile lie reasonably close with the pitot tube lying within the PIV scatter band which has an average of $3.2 \%$ in this region. Near the edge of the flow, the PIV scatter bands increase in size because the flow on the edge of the jet 


\section{Three-component Particle Image Velocimetry in a Generic Can-type Gas Turbine} Combustor

is more unsteady than the core due to mixing with the ambient air. However, the profiles do follow a similar trend even at the edges of the flow.

\section{EXPERIMENTAL RESULTS}

The velocity data was collected on planes lying lengthwise along the central axis. These planes were chosen because they would encompass a large amount of information and they were in one of the few orientations that would allow the cameras to be positioned such that large areas could be measured. The data on these planes were close to axially symmetrical throughout the length of the combustor. All the data presented in this article is freely available from the first author in quantitative form on request.

In order to allow for comparison, some data sets collected by other authors in various forms of combustor liners are shown in Fig. 8 and 9.

\subsection{In line with holes}

The velocity magnitude contours and streamlines are shown in a normal view of the combustor liner in Fig. 10a. This plane is aligned with the holes of all three zones. Fig. 10b has the three-component velocity vector field on the same plane as Fig. 10a and views of velocity profiles from the upstream direction for each of the three zones.

In Fig. 10a and 10b, with Table 3 numbering the flow phenomena, the primary zone 


\section{B C Meyers, G C Snedden, J P Meyer, T H Roos, and G I Mahmood}

reverse/return flow section can be seen at the core of the flow at (1). This region has flow velocities in the lower third of the velocity range. The jets are shown as yellow-green sectors on either side of the axial centerline (2). The primary zone jets penetrate to $100 \%$ of the radial distance into the flow. This is seen where the streamlines become asymptotic to the flow at the stagnation point. The central Primary zone jet streamline is colored magenta to highlight the impingement of the opposing jets on each other. From these two streamlines, the average initial jet angle is measured to be about $72^{\circ}$. The jet penetration can influence the rate of mixing in the combustor liner [16], which, in turn, influences the combustion process including efficiency and emissions. For this reason, the jets should be well modeled in simulations. The jets observed as part of this study correlated well with those indicated by Vakil and Thole [4] (see Fig. 8c), Lefebvre and Ballal [16] and NREC [17] (see Fig. 2b, 2c and $2 \mathrm{~d})$.

The axially symmetric position of the swirling recirculation zone above and below the centerline in both figures is shown at (3). The recirculation zone extends up until the primary zone jets. The recirculation zone is an effect of the swirling flow and its extent is affected by the jets. For this reason, the recirculation zone characteristic can be used to evaluate whether the turbulence model is capable of modeling both jets and swirling flow correctly. The recirculation zone is created due to the decrease of the static pressure at the central core just 


\section{Three-component Particle Image Velocimetry in a Generic Can-type Gas Turbine} Combustor

downstream of the swirler due to the highly swirling flow caused by the swirler $[\mathbf{1 6}, \mathbf{2 3}]$. This, in combination with the primary zone jets acting as a barrier, causes the flow to reverse along the central axis. Similar recirculation zone results can be seen in the work of Janus et al. [12] and Weigand et al. [11]. The reverse flow zone shape can also be picked up here and it appears more rectangular rather than $\mathrm{V}$ - or Y-shaped which are the more common shapes for a combustor recirculation zone [13]. Similarities of the presented primary zone data can also be seen in the primary zone air flow pattern presented by Lefebvre and Ballal [16] and NREC and shown in Fig. 2.

Some of the more subtle features that can be observed in the vector field are: The bulk flow splitting off to enter the swirler at (4); The convergence of the bulk flow to enter the annulus around the combustor liner (5); The annulus flow curving into a primary zone hole to form a jet is also evident at (6); The flow in the annulus (7) and the remaining annulus flow converging into a smaller annulus around the next zone at (8).

At (3) in the upstream views in Fig. 10b, it is shown that the vectors have three-components and that the fluid has a significant out-of-plane flow. This is expected due to the swirler. It can also be observed that for the half above the centerline, the vectors point to the left and to the right below the centerline. This indicates that the flow is swirling. It also shows that the swirl velocity decreases as one moves away from the centre towards the liner wall. This is likely 


\section{B C Meyers, G C Snedden, J P Meyer, T H Roos, and G I Mahmood}

due to the flow at the outer edge coming in closer proximity to the wall and leaving the immediate regions of the swirler influence. Similar profiles can be seen in data presented by Lefebvre and Ballal [16] (See Fig. 9) and Gupta et al. [23]. The tangential velocity profiles can be used to evaluate the turbulence model effectiveness in modeling swirling flow. A summary of the primary zone features is listed in Table 3 and shown in Fig. 10a from (1) to (8).

As with the primary zone, the secondary zone features are also shown in Fig. 10a from (9) to (14). The secondary zone jets (9) only penetrate $\pm 60 \%$ of the radial distance. This is expected due to the jets having smaller hole diameters with a smaller portion $(8.8 \%)$ of the total mass flow than the primary zone (22.5\%) [2]. The average initial jet angle of the secondary jets is about $77^{\circ}$. The penetration depth and initial jet angle in the secondary zone is evident in the jet centre streamline trajectory which is also shown in magenta in Fig. 10a. In the forward flow section, the outer part of the secondary zone flow diverges just before the jets, converges while passing the jets but then diverges again after the jets.

In the upstream view of the secondary zone, the swirl (11) is shown to be less intense than in the primary zone. Similar features were observed in the annulus region as in the primary zone shown at (12), (13) and (14).

For the dilution zone, there is an unexpected recirculation zone (16) with the centre flow in 


\section{Three-component Particle Image Velocimetry in a Generic Can-type Gas Turbine} Combustor

the reverse flow direction at (15). This atypical flow feature can be used to evaluate whether the CFD simulation is modeling real flow features. Based on the jet centre streamline (the first pair of magenta streamlines in the dilution zone), the dilution zone jets penetrate to $86 \%$ of the radial distance into the combustor (17), however, as can be seen in the downstream pair of magenta streamlines, that the outer edge of the dilution jets impinge on each other at the combustor axial centre line at the $100 \%$ radial penetration position. This deep penetration of the dilution jets likely causes the recirculation zone in the dilution region by forming a partial barrier, which then induces a recirculation zone. These jets receive the majority $(50 \%)$ of the total mass flow but the hole set has a large number of large diameter holes so the velocity of the jet decreases at a faster rate than that of the primary jets [2]. The initial jet angle is close to perpendicular in the dilution zone. The increasing initial jet angle trend from the primary zone to the dilution zone is due to a decreasing of the annulus flow velocity as the air moves along the annulus in the axial direction.

Fig. 10b shows that as the air progresses from the primary zone through the secondary zone and ends in the dilution zone, the swirling motion around the axis of the combustor becomes less intense and the axial and radial motion becomes dominant over the tangential flow. In the dilution zone, there is only a slight swirl evident (18).

A list of all the features shown in Fig. 10 are given in Table 3. 


\section{B C Meyers, G C Snedden, J P Meyer, T H Roos, and G I Mahmood}

\subsection{In between holes}

In Fig. 11a, the planes are in between the holes of each of the respective zones. The primary zone plane is at $30^{\circ}$ to the plane in line with the holes, the secondary zone is at $22.5^{\circ}$ and the dilution zone is at $18^{\circ}$. All three planes are viewed normally. In this figure, the velocity magnitude contours are shown with the streamlines superimposed.

Fig. 11b shows the velocity vector field viewed from the side and the velocity vectors viewed from the upstream direction for each of the three zones.

In the primary zone, it is evident that the flow structure is very similar to the flow in line with the holes except that the jets are missing in this flowfield. The features are pointed out as items (19) to (24) (Table 4) in Fig. 11a and 11b.

The secondary zone flow in Fig. 11a and 11b shows the central flow diverging outwards in the region where the jets were entering in the data set in line with the holes. Other than the lack of jets, the flowfield is again very similar to the flow with jets. Present in the secondary zone are the forward flow region (25) and swirling flow (26).

As in the previous two zones, in the dilution zone there are many of the same features in between the holes as in line with the holes and these are listed as (27) to (29). There is, however, a difference on the outer edges of the two recirculation zones in this section. The flow at the outer edge of the recirculation zone leaves the vortex structure and flows along the 


\section{Three-component Particle Image Velocimetry in a Generic Can-type Gas Turbine} Combustor

wall to join the bulk flow of the combustor whereas in the plane in line with the holes the recirculating flow is blocked by the jets and remains in the vortex. This difference is shown in Fig. $11 \mathrm{a}$ and $11 \mathrm{~b}$ at (30).

A list of all the features shown in Fig. 11 are given in Table 4.

\section{CONCLUSION}

The purpose of this study was to collect the three-component velocity data in a complete cantype gas turbine combustor to form part of a test case for comparison with CFD. The test case is intended to help validate CFD models and the CFD design methodology when using CFD as a design tool for gas turbine combustors. There are previous experiments performed for the comparison with CFD, however, experiments that consist of a full can-type combustor that has all the features of a gas turbine combustor are absent. The combustor presented in this study includes a swirler, primary, secondary and dilution holes as well as cooling holes. PIV data was collected in the non-reacting combustor on planes both in line with and in between the holes of each of the three zones. This data is intended to aid in the validation of the first step (the non-reacting run) in gas turbine combustor simulations which precedes the addition of combustion modeling.

The results of the PIV experiment have a large amount of detail that enables the use of the 
B C Meyers, G C Snedden, J P Meyer, T H Roos, and G I Mahmood

data as an effective test case. The size and position of the recirculation regions can be used to validate the CFD turbulence model's performance in the simulation of both jets and swirling flow together. The magnitude and shape of the tangential velocity profiles is a good tool to show how well the swirling flow was modeled. The reverse flow region in the primary zone of this particular combustor is shown to have a rectangular shape rather than the typical V- or $\mathrm{Y}$ shape. The recirculation region in the dilution zone, which is atypical, provides an additional test to ensure that real flow features are captured. The penetration depth of the jets is also a characteristic that must be well modeled using numerical techniques since the jet penetration can influence the rate of mixing in the combustor liner.

\section{FUNDING}

This work was supported by the Defence Research and Development Board under Armscor order KT471006.

\section{REFERENCES}

1 Mbatha, M. N. The Design, Manufacturing and Testing of a Fuel Injection System for a Gas Turbine Combustor. Final-year project, University of Pretoria, South Africa, 2003. 
Three-component Particle Image Velocimetry in a Generic Can-type Gas Turbine Combustor

2 Meyers, B. C. The Design, Manufacture and Testing of the Dilution Zone of a Gas

Turbine Combustor. Final-year project, University of Pretoria, South Africa, 2003.

3 Scheepers, G. Design of a Swirler for an Existing Gas Turbine Combustor. Final-year project, University of Pretoria, South Africa, 2003.

4 Vakil, S. S., and Thole, K. A. Flow and Thermal Field Measurements in a Combustor Simulator Relevant to a Gas Turbine Aeroengine. Journal of Engineering for Gas Turbines and Power, April 2005, 127, pp. 257-267. DOI: 10.11151/1.1806455.

5 Archer, S., and Gupta, A. K. Confinement Effects on Flow and Combustion under Fuel Lean Conditions. In Proceedings of IMECE04 2004 ASME International Mechanical Engineering Congress and Exposition, Anaheim, California, USA, November 2004, paper IMECE2004-60930, pp. 87-96.

6 Mandai, S., and Nishida, H. Application of Turbulent Reacting Flow Analysis for Gas Turbine Combustor Development. JSME International Journal, 2004, Series B, 47(1), pp. 108-114.

7 Li, G., and Gutmark, E. J. Boundary Condition Effects on Nonreacting and Reacting Flows in a Multiswirl Combustor. AIAA Journal, March 2006, 44(3), pp. 444-456. 
B C Meyers, G C Snedden, J P Meyer, T H Roos, and G I Mahmood

8 Eggels, R. L. G. M., and Brown, C. T. Comparison of Numerical and Experimental Results of a Premixed DLE Gas Turbine Combustor. In Proceedings of ASME Turbo Expo 2001 Power for Land, Sea, and Air, New Orleans, USA, 2001, paper no. 2001-GT0065 .

9 Diers, O., Koopman, J., Fischer, M., and Hassa, C. Investigation of Two Advanced Cooling Mixing Concepts for a Rich Quench Lean Combustor. Journal of Engineering for Gas Turbine and Power, October 2002, 124, pp. 784-791.

10 Carl, M., Behrendt, T., Fleing, C., Frodermann, M., Heinze, J., Hassa, C., Meier, U., Wolff-Gassmann, D., Hohmann, S., and Zarzalis, N. Experimenal and Numerical Investigation of a Planar Combustor Sector at Realistic Operating Conditions. Journal of Engineering for Gas Turbine and Power, October 2001, 123, pp. 810-816. DOI: 10.11151/1.1378298.

11 Weigand, P., Meiers, W., Duan, X., and Aigner, M. Laser Based Investigations of Thermo-acoustic Instabilities in a Lean Premixed Gas Turbine Model Combustor. In Proceedings of ASME Turbo Expo 2006 Power for Land, Sea, and Air, Barcelona, Spain, May 2006, paper no. GT2006-90300. 
Three-component Particle Image Velocimetry in a Generic Can-type Gas Turbine Combustor

12 Janus, B., Dreizler, A., and Janicka, J. Flow Field and Structure of Swirl Stabilized Non-Premixed Natural Gas Flames at Elevated Pressure. In Proceedings of ASME Turbo Expo 2004 Power for Land, Sea, and Air, Vienna, Austria, June 2004, paper no. GT200453340.

13 Li, G., and Gutmark, E. J. Geometry Effects on the Flow Field and the Spectral Characteristics of a Triple Annular Swirler. In Proceedings of ASME Turbo Expo 2003 Power for Land, Sea and Air, Atlanta, Georgia, USA, June 2003, paper no. GT200338799.

14 Cameron, C. D., Brouwer, J., Wood, C. P., and Samuelsen, G. S. A Detailed Characterization of the Velocity and Thermal Fields in a Model Can Combustor With Wall Jet Injection. Journal of Engineering for Gas Turbine and Power, January 1989, 111, pp. 31-35.

15 Shakariyants, S. A., van Buijtenen, J. P., and Visser, W. P. J. Generic geometry definition of the aircraft engine combustion chamber. In Proceedings of ASME Turbo Expo 2004 Power for Land, Sea, and Air, Vienna, Austria, June 2004, paper no. GT200453522. 
B C Meyers, G C Snedden, J P Meyer, T H Roos, and G I Mahmood

16 Lefebvre, A. H., and Ballal, D. R. Gas Turbine Combustion: Alternative Fuels and Emissions, 2010 (CRC Press, Taylor \& Francis Group). ISBN-13: 978-1-4200-8605-8.

17 Northern Research and Engineering Corporation (NREC). The Design and Development of Gas Turbine Combustor, Volume I: Component Theory and Practice, 1980, Woburn, Massachusetts, U.S.A.

18 Gouws, J. J. Combining a One-Dimensional Empirical and Network Solver with Computational Fluid Dynamics to Investigate Possible Modifications to a Commercial Gas Turbine Combustor. Master's Dissertation, University of Pretoria, South Africa, 2007.

19 TSI Incorporated. INSIGHT $3 G^{T M}$ Data Acquisition, Analysis, and Display Software User's Guide, P/N 1980511, Revision C, September 2005 (TSI Inc., Shoreview, USA).

20 Tecplot Incorporated Tecplot Software Package, Ver. 10.0-6-012, 1988, (Tecplot, Inc., Bellevue, USA).

21 Melling, A. Tracer particles and seeding for particle image velocimetry. Measurement Science and Technology, December 1997, 8(12), pp. 1406-1416. DOI: 10.1088/09570233/8/12/005. 
Three-component Particle Image Velocimetry in a Generic Can-type Gas Turbine Combustor

22 Makida, M., Yamada, H., Shimodaira, K., Kurosawa, Y. Development of Rich-Lean Type Full Annular Combustor for Small Aircraft Jet Engine in Jaxa TechCLEAN Project through both Experimental and Analytical Researches. In Proceedings of the XX ISABE Conference, Gothenburg, Sweden, September 12-16 2011, ISBN: 978-1-60086-895-5. paper no. ISABE-2011-1124.

23 Gupta, A. K., Lilley, D. G., and Syred, N. Swirl Flows, 1984, Energy and Engineering Science Series, Abacus Press. ISBN: 0-85626-175-0. 
B C Meyers, G C Snedden, J P Meyer, T H Roos, and G I Mahmood

\section{APPENDIX}

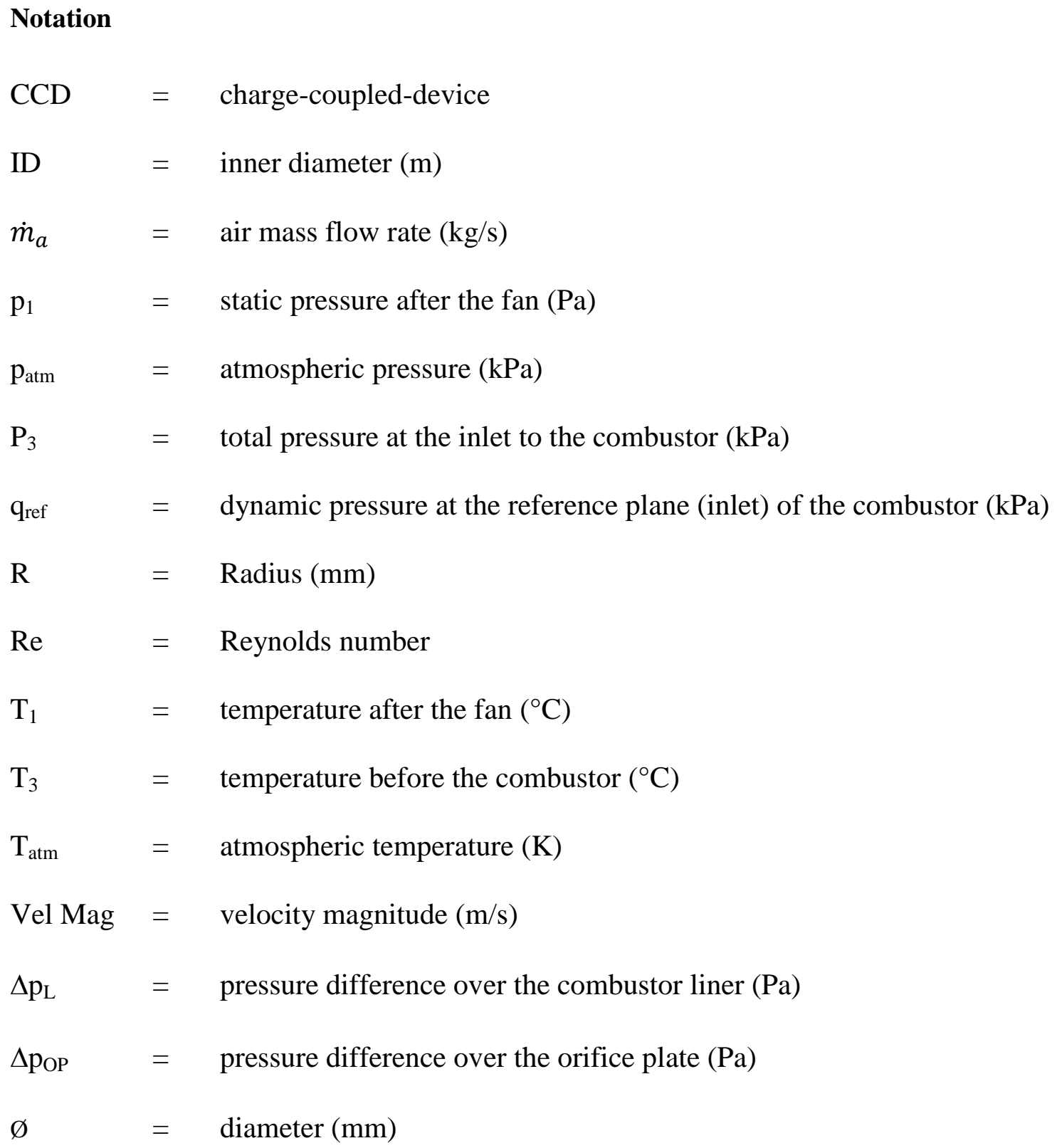


Three-component Particle Image Velocimetry in a Generic Can-type Gas Turbine Combustor

\section{LIST OF TABLE CAPTIONS}

Table 1 Experimental conditions for each experiment performed

Table 2 PIV setup and data conditions for each experiment performed

Table 3 Description of flow phenomenon identified in Fig. 10.

Table 4 Description of flow phenomenon identified in Fig. 11. 
B C Meyers, G C Snedden, J P Meyer, T H Roos, and G I Mahmood

Table 1 Experimental conditions for each experiment performed

\begin{tabular}{lc}
\hline \multicolumn{1}{c}{ Flow Characteristic } & Value \\
\hline$\dot{m}_{a}[\mathrm{~kg} / \mathrm{s}]$ & 0.056 \\
\multicolumn{1}{c}{$\mathrm{kg} / \mathrm{h}]$} & 203 \\
$\mathrm{p}_{\mathrm{atm}}[\mathrm{kPa}]$ & 86.3 \\
$\mathrm{~T}_{\mathrm{atm}}[\mathrm{K}]$ & 299 \\
$\mathrm{~T}_{1}=\mathrm{T}_{3}[\mathrm{~K}]$ & 309.5 \\
$\Delta \mathrm{p}_{\mathrm{L}}[\mathrm{Pa}]$ & 1555 \\
Overall pressure loss $[\%]$ & 1.76 \\
Pressure loss factor $[-]$ & 123.7 \\
Re $[-]$ & $3.17 \times 10^{4}$ \\
\hline \hline
\end{tabular}


Three-component Particle Image Velocimetry in a Generic Can-type Gas Turbine Combustor

Table 2 PIV setup conditions for each experiment performed

\begin{tabular}{lccccc}
\hline \hline $\begin{array}{c}\text { Experiment } \\
\text { Zone }\end{array}$ & $\begin{array}{c}\text { Pulse } \\
\text { separa- } \\
\text { tion }\end{array}$ & $\begin{array}{c}\text { Approximate } \\
\text { Field of } \\
\text { View } \\
(\mathrm{X} \times \mathrm{Y})\end{array}$ & $\begin{array}{c}\text { Approximate } \\
\text { Magnification } \\
\text { factor } \\
\text { (Top x Bottom) }\end{array}$ & $\begin{array}{c}\text { Approximate } \\
\text { Spatial } \\
\text { Resolution }\end{array}$ & $\begin{array}{c}\text { Approximate } \\
\text { Vector } \\
\text { Resolution }\end{array}$ \\
\hline \hline $\mathrm{A}$ & {$[\mu \mathrm{s}]$} & {$[\mathrm{mm}]$} & {$[\mathrm{pixels} / \mathrm{mm}]$} & {$[\mathrm{mm}]$} & {$[\mathrm{mm}]$} \\
$\mathrm{B}$ & 15 & $97 \times 101$ & $19.8 \times 17.5$ & 1.6 & 0.85 \\
$\mathrm{C}$ & 5 & $119 \times 129$ & $16.3 \times 14.5$ & 2.0 & 1.06 \\
$\mathrm{D}$ & 5 & $133 \times 143$ & $14.6 \times 13.0$ & 2.2 & 1.17 \\
$\mathrm{E}$ & 15 & $97 \times 103$ & $19.9 \times 17.7$ & 1.6 & 0.85 \\
$\mathrm{~F}$ & 5 & $122 \times 129$ & $16.2 \times 14.5$ & 2.0 & 1.07 \\
\hline \hline
\end{tabular}


B C Meyers, G C Snedden, J P Meyer, T H Roos, and G I Mahmood

Table 3 Description of flow phenomenon identified in Fig. 10.

\begin{tabular}{ll}
\hline \hline Flow phenomenon number & Flow phenomenon \\
\hline 1 & Reverse flow zone \\
2 & Primary jets \\
3 & Swirling recirculation flow \\
4 & Bulk flow splitting into swirler \\
5 & Bulk flow converging into annulus \\
6 & Annulus flow entering holes into jets \\
7 & Annulus flow \\
8 & Annulus flow converging into a smaller annulus around \\
& secondary zone \\
9 & Secondary jets \\
10 & Forward flow region \\
11 & Swirling flow \\
13 & Annulus flow entering holes into jets \\
14 & Annulus flow \\
& Annulus flow converging into a smaller annulus around \\
15 & dilution zone \\
16 & Reverse flow zone \\
18 & Recirculation zones \\
\hline \hline
\end{tabular}


Three-component Particle Image Velocimetry in a Generic Can-type Gas Turbine Combustor

Table 4 Description of flow phenomenon identified in Fig. 11.

\begin{tabular}{ll}
\hline \hline Flow phenomenon number & Flow phenomenon \\
\hline 19 & Reverse flow zone \\
20 & Swirling recirculation flow \\
21 & Bulk flow splitting into swirler \\
22 & Bulk flow converging into annulus \\
23 & Annulus flow \\
24 & Annulus flow converging into a smaller annulus around \\
& secondary zone \\
25 & Forward flow region \\
27 & Swirling flow \\
28 & Reverse flow zone \\
29 & Recirculation zones \\
30 & Slight swirling flow \\
\hline \hline
\end{tabular}


B C Meyers, G C Snedden, J P Meyer, T H Roos, and G I Mahmood

\section{LIST OF FIGURE CAPTIONS}

Fig.1 A schematic diagram of the test rig.

Fig.2 a) Main components of a conventional combustor [16]; b) Combustion chamber schematic identifying the various zones as well as typical flow patterns and air fuel distribution (modified from [17]); c) A representative primary zone [17], and d) Lucas primary-zone airflow pattern [16].

Fig.3 a) A photograph of the T56 combustor liner, and b) a schematic of the components of the T56 combustor liner [18].

Fig.4 A detailed drawing of the Perspex combustor and the various typical components.

Fig.5 A detailed drawing of the swirler.

Fig.6 a) A radial view of the experimental planes and b) an axial view of the experimental planes.

Fig.7 Comparison of the velocity profile at the outlet of the test rig.

Fig.8 a) A half section of streamline plot for isothermal flow (modified from [12]), b) A vector plot of the mean uv-velocities, zones with negative and positive $u$ velocities are marked dark grey and light grey, respectively (modified from [11]), and c) Flow field vectors downstream of the second row of dilution jets (modified from [4]). 


\section{Three-component Particle Image Velocimetry in a Generic Can-type Gas Turbine} Combustor

Fig.9 Typical profiles of axial- and swirl-velocity components in a strongly swirling flow (modified from [16]).

Fig.10 a) A contour plot of velocity magnitude along with streamlines in line with the holes and b) the velocity vector field in line with the holes viewed normal and from upstream for each zone. The numbers $1-18$ are described in Table 3.

Fig.11 a) A contour plot of velocity magnitude along with streamlines in between the holes and b) the velocity vector field in between the holes viewed normal and from upstream for each zone. The numbers 19 - 30 are described in Table 4 
B C Meyers, G C Snedden, J P Meyer, T H Roos, and G I Mahmood

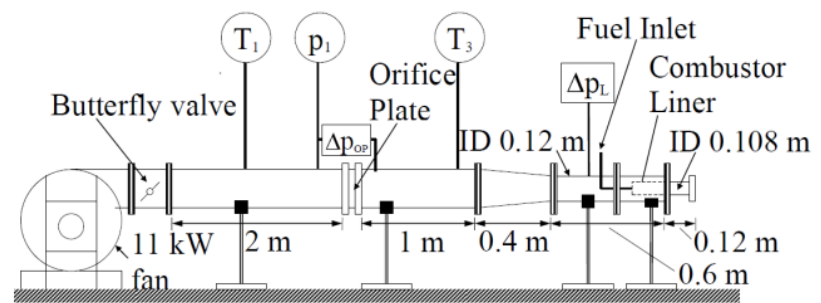

Fig.1 A schematic diagram of the test rig. 


\section{Three-component Particle Image Velocimetry in a Generic Can-type Gas Turbine} Combustor

a)

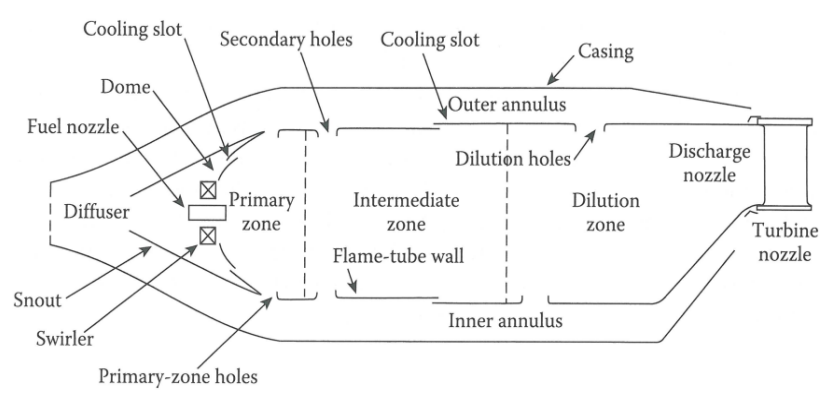

b)

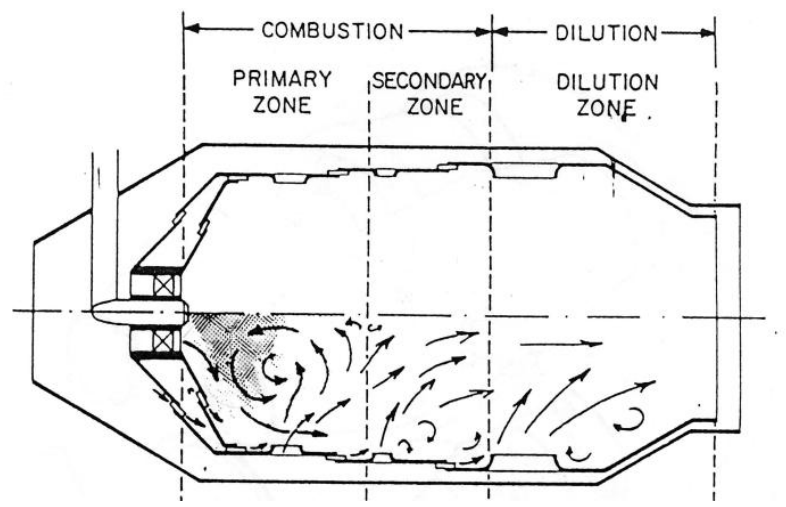

c)

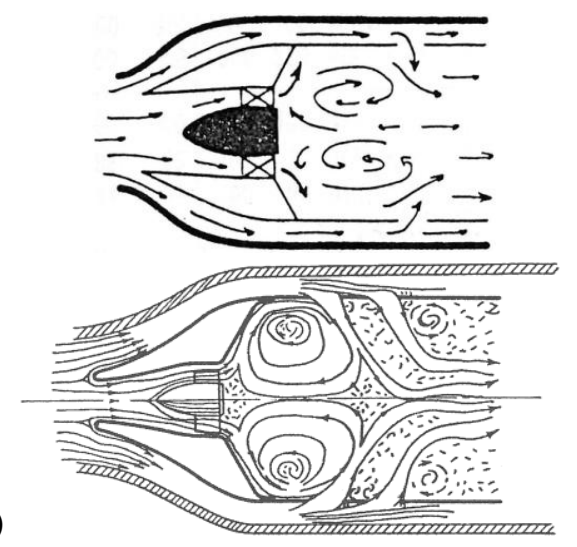

Fig.2 a) Main components of a conventional combustor [16]; b) Combustion chamber schematic identifying the various zones as well as typical flow patterns and air fuel distribution (modified from [17]); c) A representative primary zone [17], and d) Lucas primary-zone airflow pattern [16]. 
B C Meyers, G C Snedden, J P Meyer, T H Roos, and G I Mahmood

a)

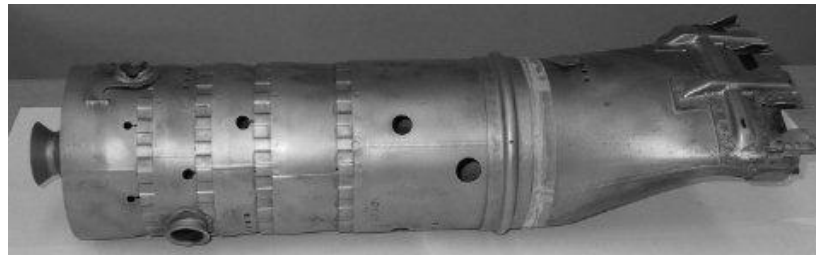

b)

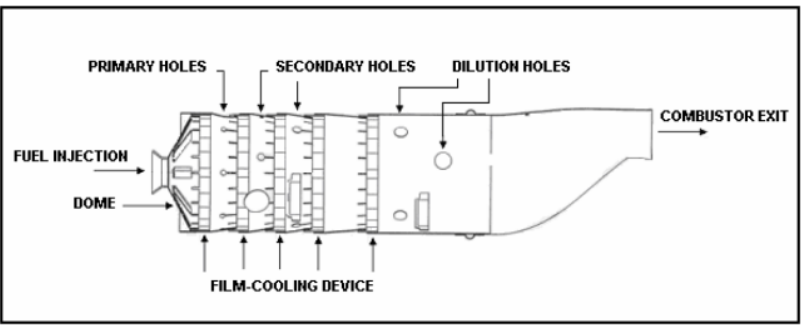

Fig.3 a) A photograph of the T56 combustor liner, and b) a schematic of the components of the T56 combustor liner [18]. 
Three-component Particle Image Velocimetry in a Generic Can-type Gas Turbine Combustor
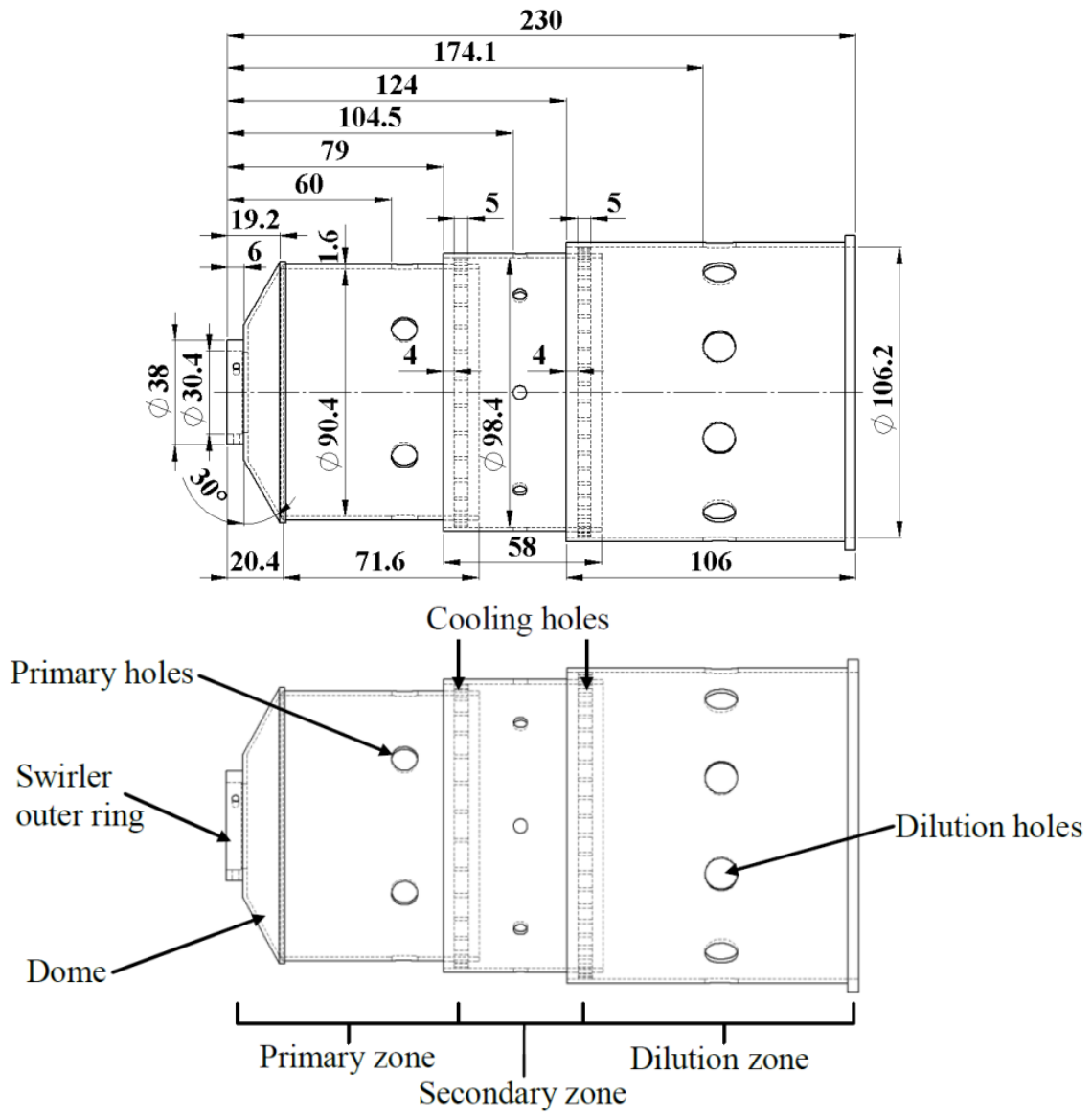

Fig.4 A detailed drawing of the Perspex combustor and the various typical components. 
B C Meyers, G C Snedden, J P Meyer, T H Roos, and G I Mahmood
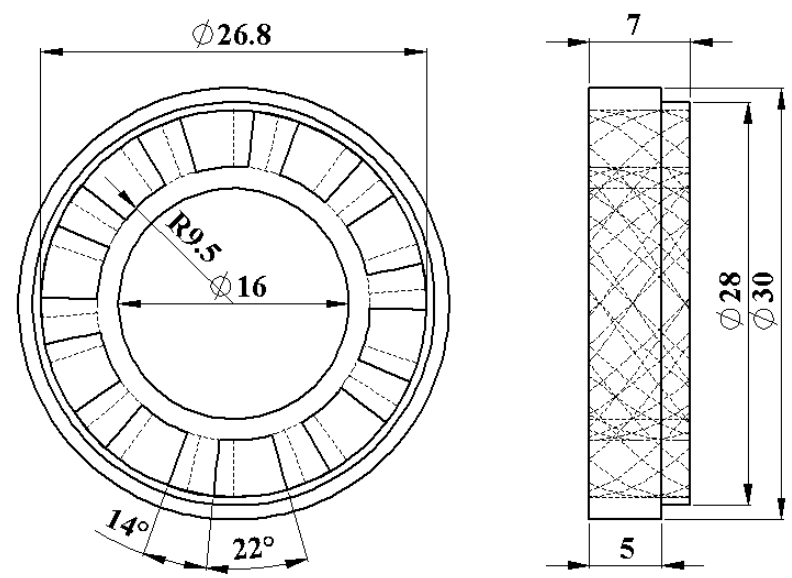

Fig.5 A detailed drawing of the swirler. 
Three-component Particle Image Velocimetry in a Generic Can-type Gas Turbine Combustor
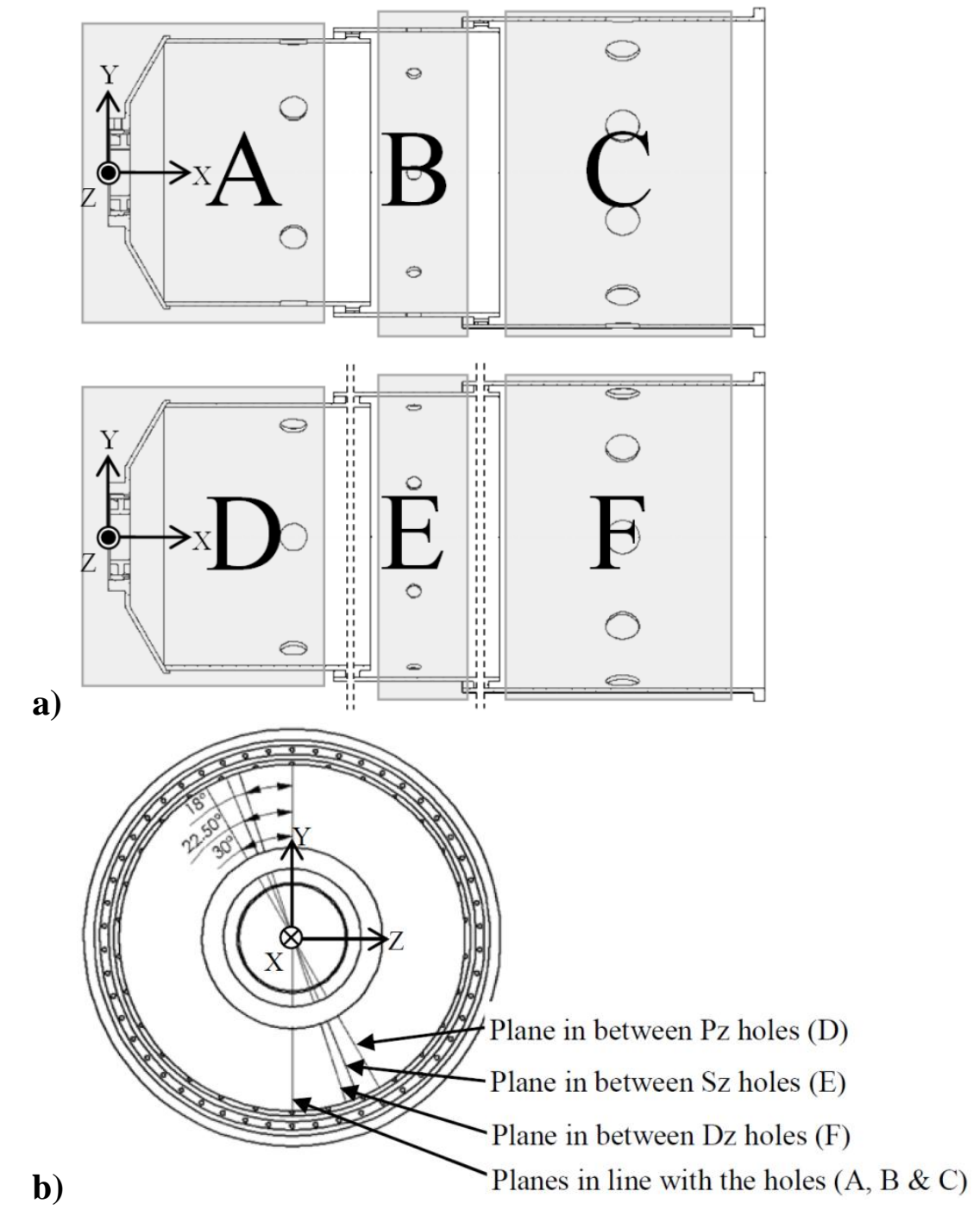

Fig.6 a) A radial view of the experimental planes and b) an axial view of the experimental planes. 
B C Meyers, G C Snedden, J P Meyer, T H Roos, and G I Mahmood

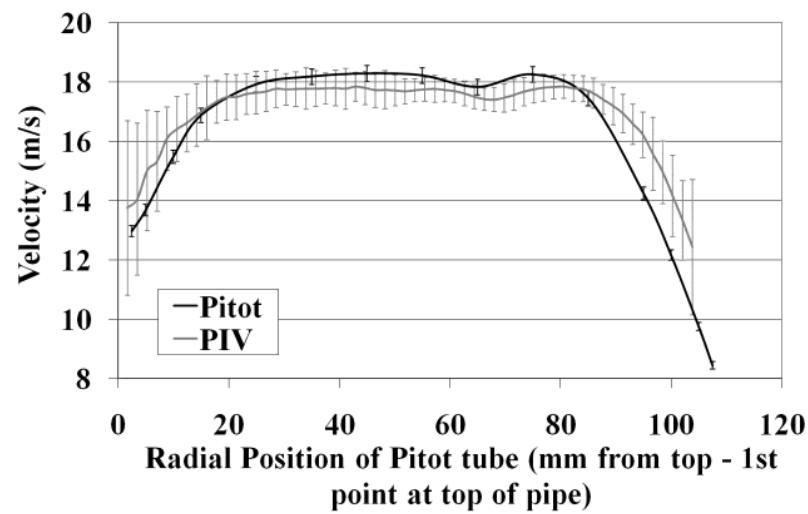

Fig.7 Comparison of the velocity profile at the outlet of the test rig. 
Three-component Particle Image Velocimetry in a Generic Can-type Gas Turbine Combustor

a)
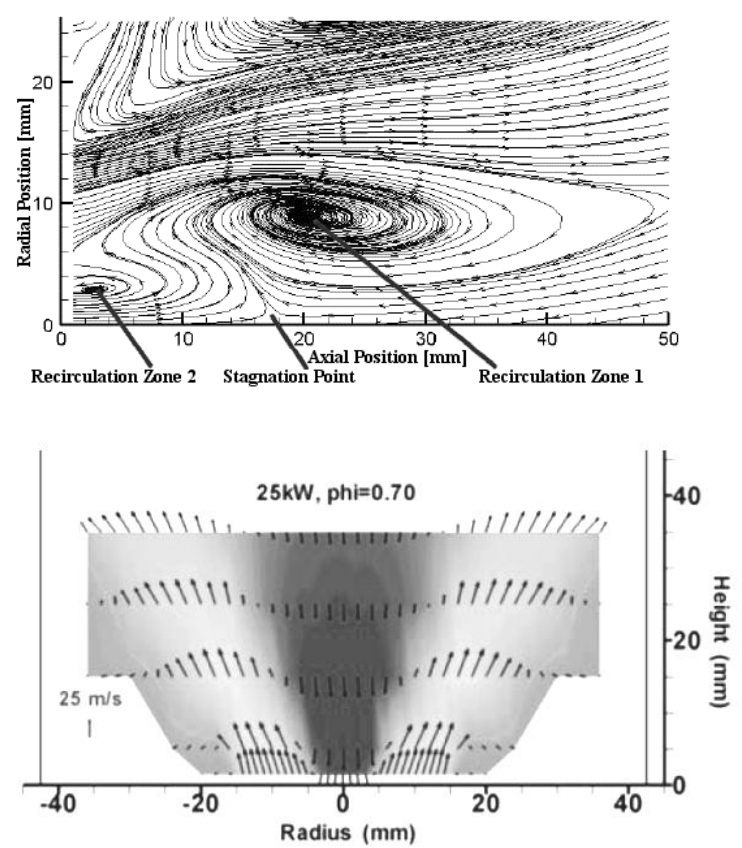

b)

Radius (mm)

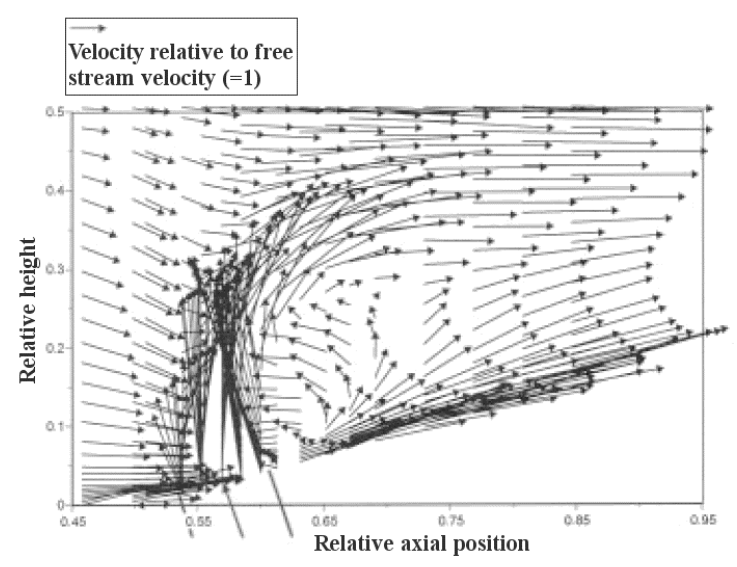

Fig.8 a) A half section of streamline plot for isothermal flow (modified from [12]), b) A vector plot of the mean uv-velocities, zones with negative and positive $u$ velocities are marked dark grey and light grey, respectively (modified from [11]), and c) Flow field vectors downstream of the second row of dilution jets (modified from [4]). 
B C Meyers, G C Snedden, J P Meyer, T H Roos, and G I Mahmood

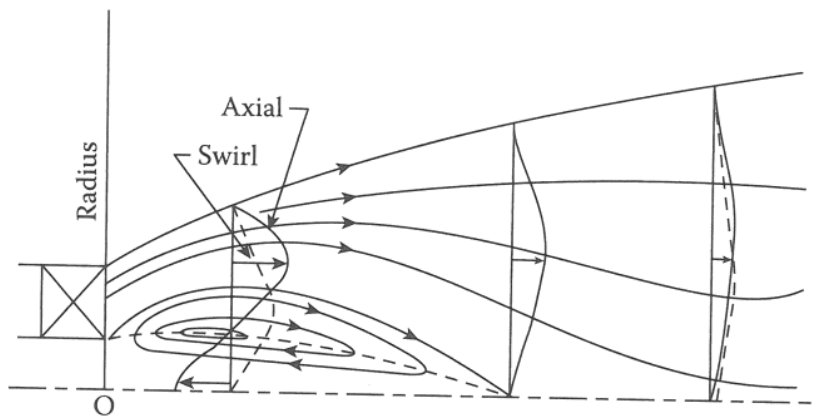

Fig.9 Typical profiles of axial- and swirl-velocity components in a strongly swirling flow (modified from [16]). 
Three-component Particle Image Velocimetry in a Generic Can-type Gas Turbine Combustor

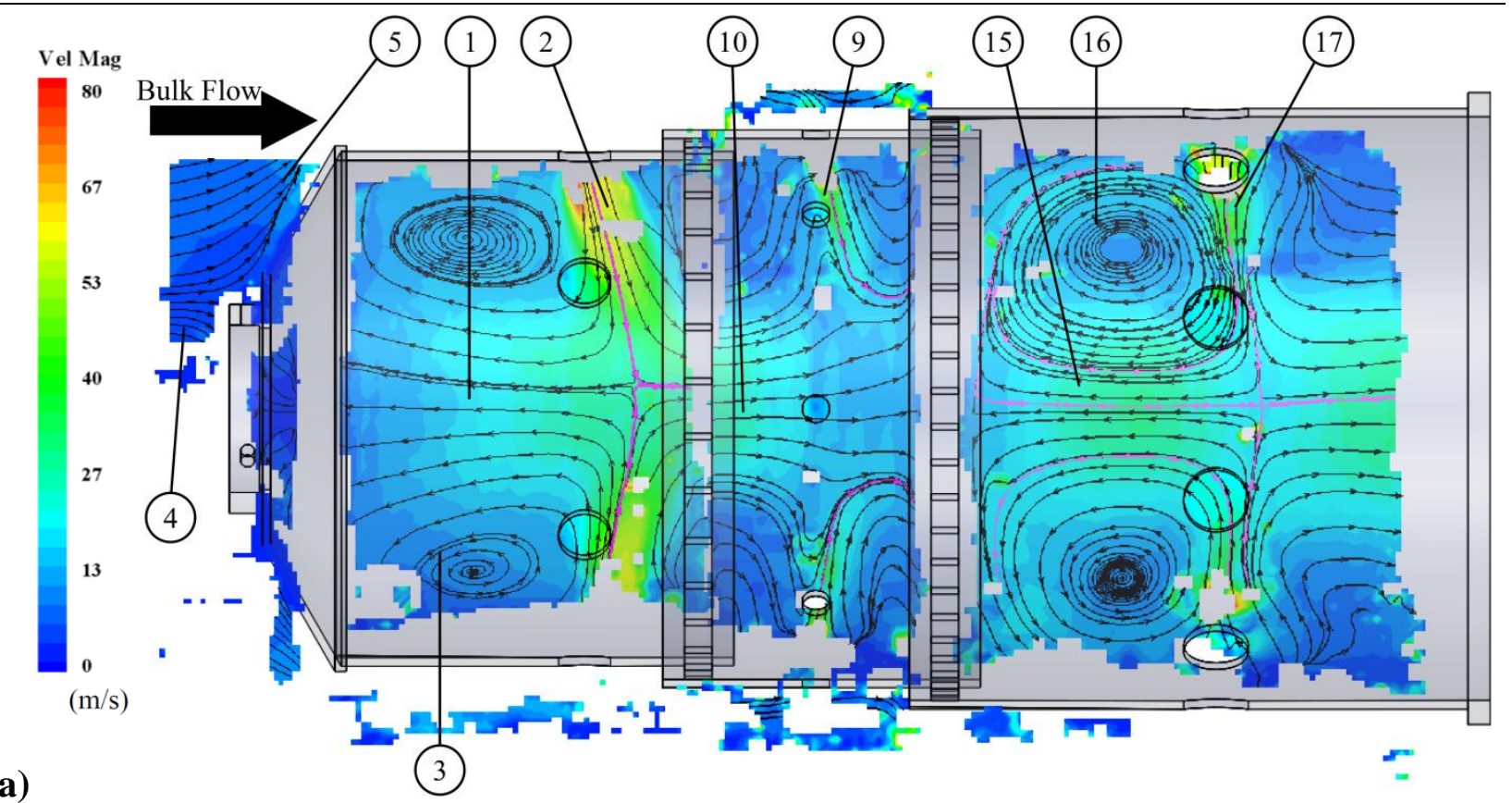

a)

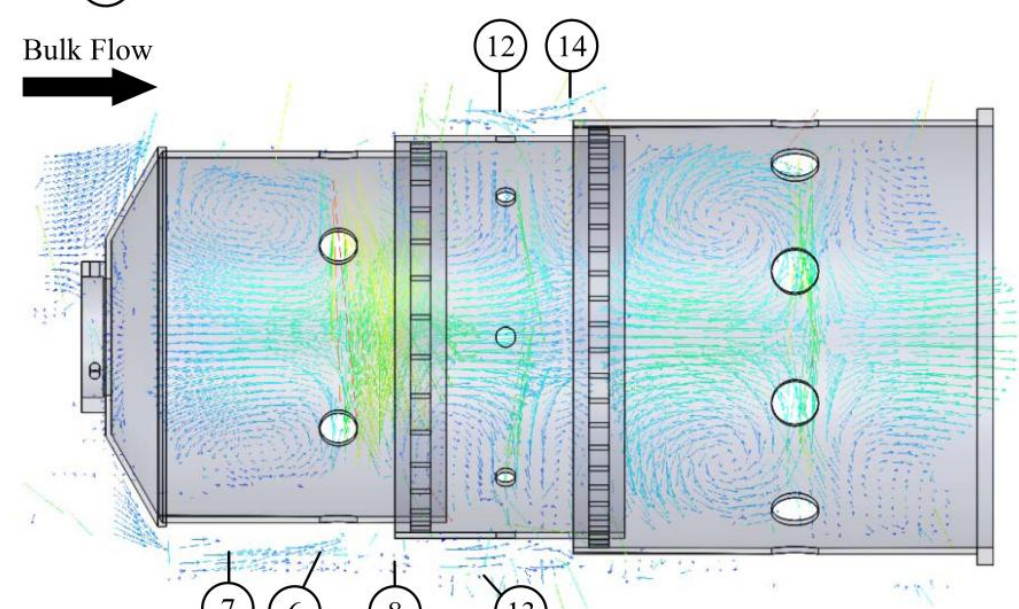

(7) 6 (8) (13)

$\otimes$

Bulk Flow
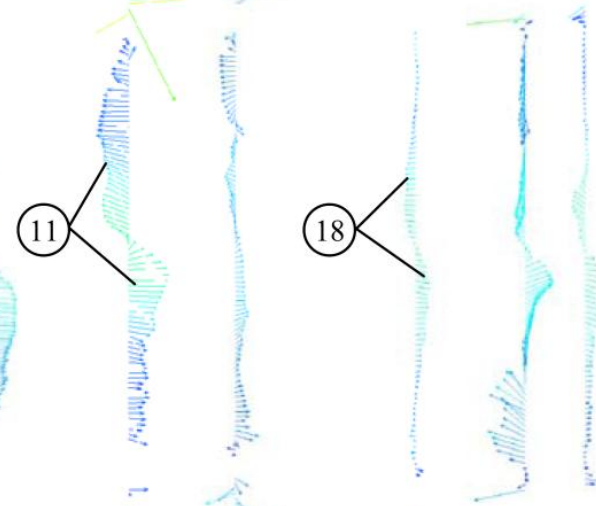

b)

Fig.10 a) A contour plot of velocity magnitude along with streamlines in line with the holes and b) the velocity vector field in line with the holes viewed normal and from upstream for each zone. The numbers $1-18$ are described in Table 3. (The symbol $\otimes$ used above is to show the bulk inlet flow is into the page with respect to the profiles shown.) 

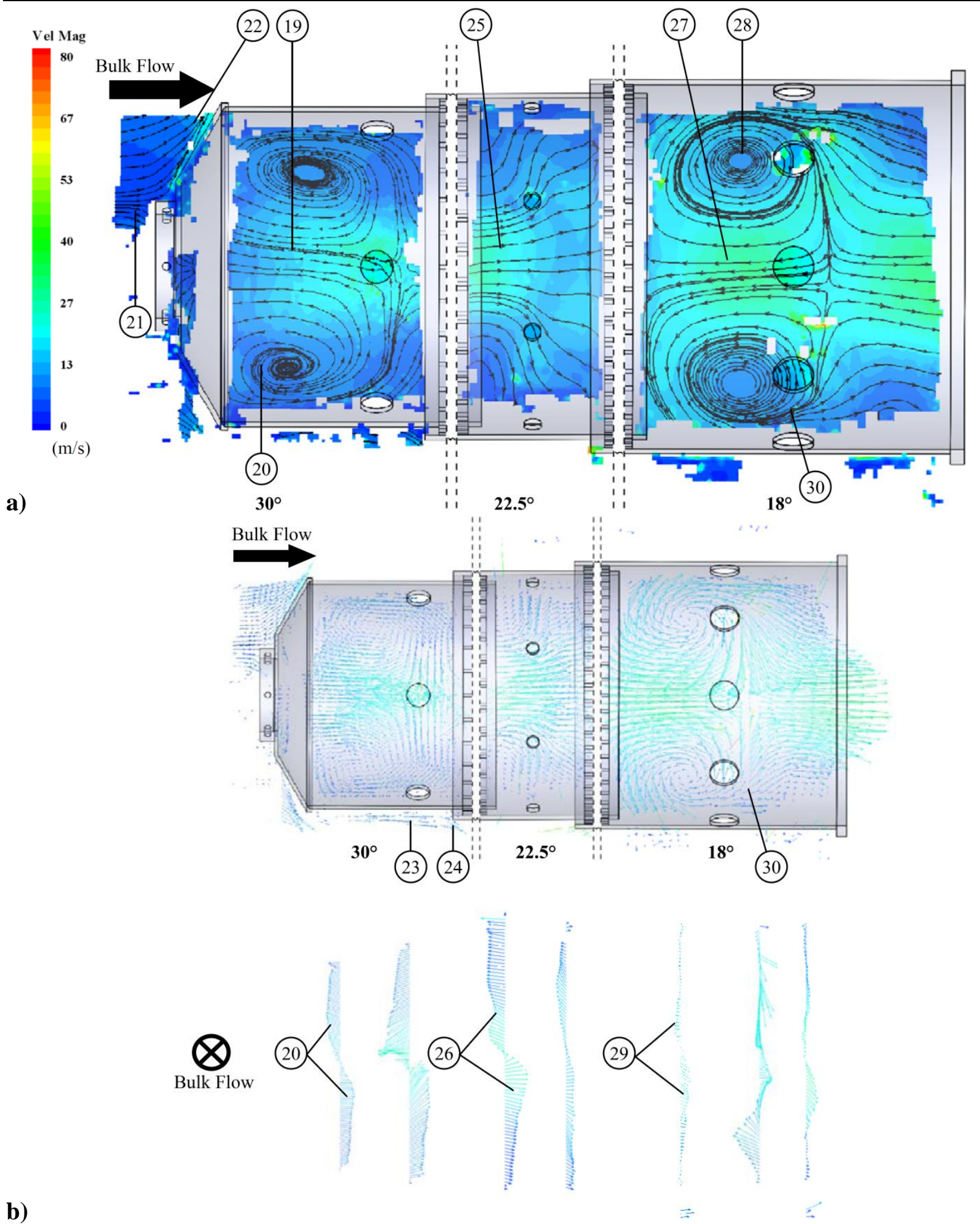

b)

Fig.11 a) A contour plot of velocity magnitude along with streamlines in between the holes and b) the velocity vector field in between the holes viewed normal and from upstream for each zone. The numbers 19 - 30 are described in Table 4. (The symbol $\otimes$ used above is to show the bulk inlet flow is into the page with respect to the profiles shown.) 